\title{
Urinary enterolactone associated with liver enzyme levels in US adults: National Health and Nutrition Examination Survey (NHANES)
}

\author{
Cheng $\mathrm{Xu}^{1,2} \dagger$, Qian $\mathrm{Liu}^{1,2} \dagger$, Qunwei Zhang ${ }^{3}$, Zhao-Yan Jiang ${ }^{4 *}$ and Aihua Gu ${ }^{1,2 *}$ \\ ${ }^{1}$ State Key Laboratory of Reproductive Medicine, Institute of Toxicology, Nanjing Medical University, \\ No. 818 Tianyuan East Road, Nanjing 211166, People's Republic of China \\ ${ }^{2}$ Key Laboratory of Modern Toxicology of Ministry of Education, School of Public Health, Nanjing Medical University, \\ No. 818 Tianyuan East Road, Nanjing 211166, People's Republic of China \\ ${ }^{3}$ Department of Environmental and Occupational Health Sciences, School of Public Health and Information Health \\ Sciences, University of Louisville, Louisville, KY 40292, USA \\ ${ }^{4}$ Department of Surgery, Shanghai Institute of Digestive Surgery, Ruijin Hospital, Shanghai JiaoTong University \\ School of Medicine, No. 197 Ruijin Er Road, Shanghai 200025, People's Republic of China
}

(Submitted 21 January 2015 - Final revision received 11 March 2015 - Accepted 9 April 2015 - First published online 20 May 2015)

\section{Abstract}

Phyto-oestrogens are a family of plant-derived xeno-oestrogens that appear to have beneficial effects on human health. To date, no data are available about phyto-oestrogen consumption affecting liver health in a population. The present study aimed to explore the relationship of urinary phyto-oestrogen metabolites with serum liver enzymes in US adults. A nationally representative sample of US adults in the National Health and Nutrition Examination Survey (NHANES) 2003-10 was analysed. The cross-sectional study sample consisted of 6438 adults with data on urinary phyto-oestrogen levels, serum alanine aminotransferase (ALT), aspartate aminotransferase (AST), alkaline phosphatase (ALP) and $\boldsymbol{\gamma}$-glutamyl transaminase (GGT) concentrations and data on other potential confounders. Multivariate logistic regression and linear regression were applied to assess associations between urinary phyto-oestrogen levels and ALT, AST, ALP and GGT concentrations. We found a remarkable association between urinary enterolactone and GGT in both adult males (OR $0 \cdot 37,95 \%$ CI $0 \cdot 22,0 \cdot 61$; $P=0.003)$ and females (OR 0.37, 95\% CI 0.26, 0.54; $P=0.009)$. Moreover, elevated enterolactone levels were inversely associated with ALT and AST levels in adult males. However, no association was present between levels of urinary daidzein, $O$-desmethylangolensin, equol, enterodiol or genistein with liver enzyme levels in this population. The present study results provide epidemiological evidence that urinary enterolactone levels are associated with liver GGT levels in humans. This suggests a potential protective effect of enterolactone on human liver function. However, the underlying mechanisms still need further investigation.

\section{Key words: Phyto-oestrogens: Cross-sectional studies: Liver enzymes: Enterolactone}

Phyto-oestrogens are present in vegetables, fruits and whole grains, which are consumed daily by humans. In general, phyto-oestrogens can be classified into chalcones, flavonoids (flavones, flavonols, flavanones, isoflavonoids), lignans and stilbenoids according to their chemical structures ${ }^{(1)}$. Because of their structural similarity to oestrogen, they can bind to oestrogen receptors $(\mathrm{ER})^{(2,3)}$. Although the affinities of phyto-oestrogens for ER are low, they can still exert strong biological effects because of their higher levels in serum ${ }^{(4)}$, having antioxidant, anti-proliferative, anti-mutagenic and anti-angiogenic effects. Previous studies have shown that phyto-oestrogens have beneficial effects in protecting from breast cancer ${ }^{(5)}$, prostate cancer $^{(6)}$, cardiovascular risk ${ }^{(7)}$ and metabolic syndrome ${ }^{(8)}$.

The liver is the organ that metabolises substances such as nutrients, drugs and toxins. It is important in regulating and maintaining homeostasis of carbohydrates, proteins and lipids in the body. It also plays a crucial role in the enterohepatic recycling of several substances such as bile acids, cholesterol and others. Liver aminotransferases - alanine aminotransferase (ALT), aspartate aminotransferase (AST) and alkaline phosphatase (ALP) - are markers commonly used in routine liver function tests as markers of diseases of

\footnotetext{
Abbreviations: ALP, alkaline phosphatase; ALT, alanine aminotransferase; AST, aspartate aminotransferase; ER, oestrogen receptor; GGT, $\boldsymbol{\gamma}$-glutamyl transaminase; NHANES, National Health and Nutrition Examination Survey.
}

*Corresponding authors: A. Gu, email aihuagu@njmu.edu.cn; Z.-Y. Jiang, email zhaoyanjiang@gmail.com

†These authors contributed equally to the present study and should be regarded as joint first authors. 
the liver or bile ducts, as is $\gamma$-glutamyl transaminase (GGT) Enzyme levels increase when hepatocytes are damaged under disease conditions such as hepatitis, cholestasis, severe steatosis and others. Whether phyto-oestrogens are associated with liver diseases in humans has not been clarified. Some animal studies suggest that phyto-oestrogens themselves are capable of antioxidant activity and protecting against liver toxicity ${ }^{(9-11)}$. No epidemiologic studies have directly evaluated the relationship between urinary phytooestrogens and levels of liver enzymes.

The National Health and Nutrition Examination Survey (NHANES) studies were conducted by the US National Center for Health Statistics (Centers for Disease Control and Prevention, Atlanta, GA, USA) ${ }^{(12)}$. NHANES studies are crosssectional studies designed to evaluate the health and nutritional status of a representative sample of the civilian non-institutionalised US population using a complex stratified multi-stage sampling design. In the present study, we investigated the associations between urinary phyto-oestrogens and serum levels of four enzymes (ALT, AST, ALP and GGT) in the US population from the NHANES 2003-10 survey.

\section{Materials and methods}

\section{Data source and study population}

Data from the 2003-10 NHANES were used in this study. The data on subjects enrolled in the present study were obtained from four cycles of the NHANES (2003-4, 2005-6, 2007-8 and 2009-10). All data and detailed survey protocols from the website of the National Center for Health Statistics were retrieved. The study was approved by the National Center for Health Statistics Research Ethics Review Board.

\section{Urinary phyto-oestrogen measurement}

Phyto-oestrogen metabolites were measured in spot urine samples from participants. Spot urine samples were collected at NHANES mobile examination centres in collection cups. They were processed, stored and shipped to the Division of Environmental Health Laboratory Sciences, National Center for Environmental Health, Centers for Disease Control and Prevention for analysis (for details see NHANES Laboratory/Medical Technologists Procedures Manual). Urinary phyto-oestrogens were analysed by HPLC-atmospheric pressure photo-ionisationtandem MS (Laboratory procedure manual; see http:// wwwn.cdc.gov/nchs/nhanes/2009-2010/PHYTO_F.htm). Subsequently, the components were resolved by reverse-phase HPLC. MS with internal isotope-labelled standards was used to assure the proper accuracy and detection limit. Urinary phytooestrogens were creatinine-standardised to correct for urine dilution and creatinine was measured using Beckman Synchron CX3 Clinical Analyser at the University of Minnesota.

\section{Liver enzyme measurement}

Serum specimens were refrigerated and shipped to a central laboratory for analysis. The Collaborative Laboratory Services used a Beckman Synchron LX20 analyser to measure the biochemistry profile, including levels of ALT, AST, ALP and GGT. The upper reference limits recommended by the NHANES 2001-10 were used to define an abnormal status of ALT ( $>47 \mathrm{U} / 1$ in men or $>30 \mathrm{U} / 1$ in women), AST $(>33 \mathrm{U} / 1$ in men and women), ALP ( $>113 \mathrm{U} / 1$ in men and women) and GGT $(>65 \mathrm{U} / 1 \text { in men or }>36 \mathrm{U} / 1 \text { in women })^{(13)}$.

\section{Covariates}

The NHANES 2003-10 collected a wide range of sociodemographic variables including age, sex, race and ethnicity, education and cotinine level, and behavioural risk factors such as alcohol drinking. In addition, NHANES participants reported medical conditions, including diabetes. BMI (body weight divided by height squared, $\mathrm{kg} / \mathrm{m}^{2}$ ) was measured by trained examiners. Fibre intake was assessed via a 24-h recall dietary interview. We also obtained data on hepatitis $\mathrm{B}$ infection status (infection defined as surface antigen or core antibody positive) and hepatitis $\mathrm{C}$ (infection defined as antibody positive) from laboratory examinations.

\section{Statistical methods}

To investigate the relationship of phyto-oestrogen exposure to abnormal liver enzyme levels, we used weighted multiple variable logistic regression and presented the associations with OR and 95\% CI. We also examined the distribution of ALT, AST, ALP and GGT levels and performed log transformation to approximate a normal distribution. The associations between urinary phyto-oestrogen level and continuous enzyme levels were assessed using weighted multiple variable linear regression models. We presented multivariate adjusted geometric means and 95\% CI of liver enzyme levels by quartiles of urinary phyto-oestrogens. As sex is an extremely crucial variable, we conducted separate analyses stratified by sex. Diabetes was considered a potential mediator and was examined in separate models with the aforementioned covariates. All multivariate models were performed after adjusting for age, sex, race and ethnicity, education, BMI, cotinine, alcohol consumption, fibre intake and hepatitis $\mathrm{B}$ or hepatitis $\mathrm{C}$ positivity. Diabetes, BMI and alcohol consumption were not retained in the final models, because adjusting for these variables did not change the results substantially ( $<5 \%$ of change in effect estimates). The lowest quartile (quartile 1) was used as the reference value. In addition, a test for trend of the OR was performed to evaluate the association of elevated liver enzyme levels with phytooestrogen exposure and phyto-oestrogen quintiles coded as ordinal variables. Statistical Analysis Systems statistical software package version 9.2 (SAS Institute, Inc.) was performed for all statistical analyses. A $P$ value $<0.05$ was designated as the cut-off for statistical significance.

\section{Results}

Of the 41156 participants of the NHANES 2003-10, we excluded those who were aged less than 20 years ( $n$ 18983), 


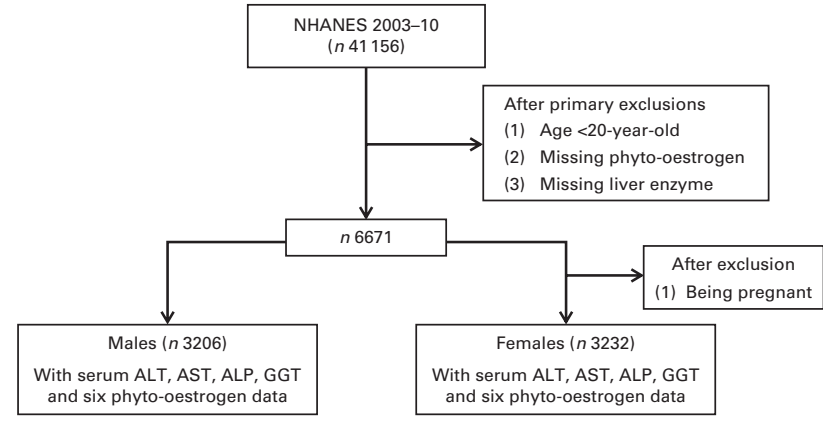

Fig. 1. Schematic diagram depicting adult National Health and Nutrition Examination Survey (NHANES) 2003-10 subjects. ALT, alanine aminotransferase; AST, aspartate aminotransferase; ALP, alkaline phosphatase; GGT, $\gamma$-glutamyl transaminase.

or who had missing urinary phyto-oestrogen levels ( $n$ 15502). The final analytic population included 6438 participants (3206 males and 3232 females; Fig. 1). Table 1 showed the baseline characteristics and mean concentrations of urinary phytooestrogen metabolite levels (standard error). Among the entire population, $7 \cdot 4 \%$ of males and $5.4 \%$ of females were positive for hepatitis $\mathrm{B}$ infection, and $2.5 \%$ of males and $1.2 \%$ of females were positive for hepatitis $\mathrm{C}$ infection. Also, $11 \%$ of males and $12.0 \%$ of females had a history of diabetes.

First, we analysed the data with the weighted multiple variable linear regression models. We found a significant association between urinary enterolactone and serum GGT levels in males, with a decreasing trend $(P$ for trend $=0.02$, Table 2). No other significant association was present for urinary enterolactone with ALT, AST and ALP in either males or in females. There was no significant association of the five other phyto-oestrogens with liver enzymes (online supplementary Table S1)

In the multiple variable logistic regression of the association between urinary phyto-oestrogens and liver enzymes after adjustment for several confounders, a higher urinary enterolactone was associated with lower odds for elevated liver enzymes, both in males and in females (Table 3). Compared with those participants with the lowest urinary enterolactone concentration, those with highest concentration had a markedly reduced GGT level in males (OR $=0.37,95 \%$ CI $0 \cdot 22,0 \cdot 61$; $P=0.003)$ and in females (OR $=0.37,95 \%$ CI $0.26,0.54$; $P=0.009)$. Similar associations were observed between the highest urinary enterolactone level with ALT level (OR $=0 \cdot 40$, 95\% CI 0.24, 0.66; $P=0.004)$ and AST level (OR $=0.58,95 \%$ CI $0.41,0.81 ; P=0.01)$ in males. However, none of the other levels of five phyto-oestrogens was associated with liver enzyme levels (online supplementary Table S2).

Hepatitis virus infection may affect liver enzymes because of different degrees of hepatocyte damage. To exclude the possibility of such inference, a total of 484 adults positive for hepatitis $\mathrm{B}$ or hepatitis $\mathrm{C}$ virus were excluded in the next analysis (Table 4). Consistent with the aforementioned results, the highest urinary enterolactone concentration was still markedly associated with a lower odds of having elevated levels of GGT both in males (OR $=0.32,95 \%$ CI $0 \cdot 18,0 \cdot 56$; $P=0.003)$ and in females $(\mathrm{OR}=0.35,95 \%$ CI $0.23,0.52$
$P=0 \cdot 02$ ). Similarly, we found marked associations between the ALT and AST levels in males and ALP level in females. These data suggested that urinary enterolactone per se was associated with liver enzymes despite the presence of hepatitis virus infection

\section{Discussion}

With a large sample from the US NHANES 2003-10 survey, we showed that urinary enterolactone concentration was inversely associated with serum GGT levels in both sexes Furthermore, urinary enterolactone was inversely associated with AST and ALP levels in males as well.

Table 1. Weighted characteristics of National Health and Nutrition Examination Survey (NHANES) 2003-10 participants

(Mean values and standard errors; percentages)

\begin{tabular}{|c|c|c|c|c|}
\hline \multirow[b]{2}{*}{ Characteristic } & \multicolumn{2}{|c|}{$\begin{array}{c}\text { Male } \\
(n \text { 3206) }\end{array}$} & \multicolumn{2}{|c|}{$\begin{array}{l}\text { Female } \\
\text { (n 3232) }\end{array}$} \\
\hline & Mean & SE & Mean & SE \\
\hline Daidzein (ng/ml) & 385 & 28.8 & 359 & 26.5 \\
\hline O-Desmethylangolensin $(\mathrm{ng} / \mathrm{ml})$ & 70.5 & 9.94 & 107 & $12 \cdot 9$ \\
\hline Equol $(\mathrm{ng} / \mathrm{ml})$ & $45 \cdot 0$ & $6 \cdot 85$ & 57.4 & 8.94 \\
\hline Enterodiol (ng/ml) & 154 & $14 \cdot 7$ & 148 & 14.7 \\
\hline Enterolactone $(\mathrm{ng} / \mathrm{ml})$ & 879 & $49 \cdot 1$ & 799 & $47 \cdot 1$ \\
\hline Genistein $(\mathrm{ng} / \mathrm{ml})$ & 187 & $15 \cdot 1$ & 164 & $12 \cdot 8$ \\
\hline Log daidzein & 1.82 & 0.01 & 1.75 & 0.01 \\
\hline Log O-desmethylangolensin & 0.58 & 0.02 & 0.60 & 0.02 \\
\hline Log equol & 0.83 & 0.01 & 0.79 & 0.01 \\
\hline Log enterodiol & 1.55 & 0.01 & 1.50 & 0.01 \\
\hline Log enterolactone & 2.43 & 0.01 & $2 \cdot 38$ & 0.01 \\
\hline Log genistein & 1.51 & 0.01 & 1.43 & 0.01 \\
\hline Creatinine $(\mathrm{mg} / \mathrm{dl})$ & 146 & 1.48 & 106 & 1.23 \\
\hline Dietary fibre $(\mathrm{g})$ & 17.5 & 0.18 & $14 \cdot 3$ & 0.13 \\
\hline BMI $\left(\mathrm{kg} / \mathrm{m}^{2}\right)$ & 28.6 & 0.11 & 29.2 & 0.13 \\
\hline \multicolumn{5}{|l|}{ Age $(\%)$} \\
\hline $20-34$ years & $26 \cdot 7$ & & $25 \cdot 6$ & \\
\hline $35-49$ years & $25 \cdot 5$ & & $26 \cdot 9$ & \\
\hline $50-64$ years & 23.5 & & $24 \cdot 2$ & \\
\hline $65-85$ years & $24 \cdot 3$ & & $23 \cdot 3$ & \\
\hline \multicolumn{5}{|l|}{ Ethnicity (\%) } \\
\hline Mexican American & 18.9 & & $19 \cdot 3$ & \\
\hline Other Hispanic & $6 \cdot 6$ & & $7 \cdot 6$ & \\
\hline Non-Hispanic White & $50 \cdot 2$ & & $47 \cdot 7$ & \\
\hline Non-Hispanic Black & $20 \cdot 2$ & & $20 \cdot 6$ & \\
\hline Other race & $4 \cdot 1$ & & 4.8 & \\
\hline \multicolumn{5}{|l|}{ Education (\%) } \\
\hline Less than high school/GED & $15 \cdot 6$ & & $15 \cdot 7$ & \\
\hline High school/GED & 24.9 & & $23 \cdot 7$ & \\
\hline High than high school/GED & $46 \cdot 3$ & & $48 \cdot 3$ & \\
\hline \multicolumn{5}{|l|}{ BMI (\%) } \\
\hline$<25 \mathrm{~kg} / \mathrm{m}^{2}$ & 27.4 & & 31.4 & \\
\hline $25-30 \mathrm{~kg} / \mathrm{m}^{2}$ & 37.4 & & $29 \cdot 6$ & \\
\hline$>30 \mathrm{~kg} / \mathrm{m}^{2}$ & 33.9 & & 38.0 & \\
\hline \multicolumn{5}{|l|}{ Cotinine level (\%) } \\
\hline$<0.01 \mathrm{ng} / \mathrm{ml}$ (limit of detection) & 13.9 & & 23.5 & \\
\hline $0.01-10 \mathrm{ng} / \mathrm{ml}$ & $50 \cdot 9$ & & $51 \cdot 2$ & \\
\hline$>10 \mathrm{ng} / \mathrm{ml}$ & 30.9 & & $20 \cdot 3$ & \\
\hline \multicolumn{5}{|l|}{ Alcohol (\%) } \\
\hline Non-drinker & 14.7 & & $36 \cdot 7$ & \\
\hline Drinker & $78 \cdot 3$ & & $54 \cdot 0$ & \\
\hline HBsAg or HBcAb positive (\%) & 7.4 & & $5 \cdot 4$ & \\
\hline Hepatitis C antibody positive (\%) & 2.5 & & $1 \cdot 2$ & \\
\hline Diabetes (\%) & 11.0 & & $12 \cdot 0$ & \\
\hline
\end{tabular}

GED, General Educational Development; HBsAg, hepatitis B surface antigen HBcAb, Hepatitis B core antibody. 
Only a few rare interventional studies have suggested that a single phyto-oestrogen or phyto-oestrogen mixture supplement might affect liver enzymes in human subjects. However, the results are somewhat conflicting. Engelhardt \& Riedl ${ }^{(14)}$ found a remarkable increase in GGT levels among men treated with a daily dose of $60 \mathrm{mg}$ of phyto-oestrogen-containing food supplements for 1 year. One randomised controlled trial indicated that GGT decreased, while AST, ALT and ALP were normal among fifty-four healthy post-menopausal women who were administrated isoflavones for 6 months ${ }^{(15)}$. Conversely, another randomised controlled trial study in healthy post-menopausal women assigned to Pueraria mirifica (a type of plant that contains mixed phyto-oestrogens) for 24 weeks showed no significant difference in liver function ${ }^{(16)}$. To our knowledge, this is the first epidemiological study to evaluate the association between phyto-oestrogens and liver enzymes using large samples from US NHANES data. The present study results indicated an inverse association between urinary enterolactone and liver enzyme levels.

Phyto-oestrogens have chemical structures similar to oestrogen in mammals and thus they bind to $\mathrm{ER}^{(2,3,17)}$. The processes of oestrogen-induced regulation, such as inducing sex hormone binding globulin and inhibiting aromatase may be influenced by phyto-oestrogens as well ${ }^{(18)}$. Since ER are widely distributed in various tissues such as the central nervous system, gonads, lung, bones, reproductive tract, placenta and gastrointestinal tract, phyto-oestrogens may exert tissue-specific hormonal effects ${ }^{(2,19,20)}$. Furthermore, phyto-oestrogens exert an effect through ER-independent pathways by activating insulin-like growth factor-1 receptors ${ }^{(21)}$ or serotoninergic receptors $^{(22)}$, hence inducing DNA methylation ${ }^{(17,23)}$, histone modification and RNA expression ${ }^{(17)}$ and impacting tyrosine kinase, cyclic AMP/protein kinase A, cyclic GMP/NO, phosphatidylinositol-3 kinase/Akt and mitogen-activated protein (extracellular signal-regulated kinase (ERK) 1 and 2, p38) kinases ${ }^{(21-24)}$; transcription factors like NF-кB, DNA topoisomerase activities ${ }^{(21,23)}$; and other molecular mechanisms of the cell cycle and apoptosis. They can be responsible for the promotion of human health by acting as antioxidants and/or anti-mutagenics ${ }^{(18,19,21,23,25-28)}$.

Although we found an association of urinary phytooestrogens, particularly enterolactone, with liver enzyme levels, the mechanism accounting for the association is unclear. Possible mechanisms can be explained by evidence from rodent studies that showed potential hepatoprotective effects of phytooestrogens. Fan et al. ${ }^{(11)}$ showed that genistein can prevent and protect against oxidative stress-induced liver toxicity by altering the metabolism process and the activity of antioxidant enzymes in male mice. Furthermore, daidzein could exert hepatoprotective effects on female mice by its antioxidant activity in reducing apoptosis in the liver ${ }^{(9)}$. Similarly, Wong et al. ${ }^{(29}$ 'showed a marked improvement in oxidant-induced liver injury in male rats after administration of daidzein. Collectively, these data provide evidence that the beneficial effects of phyto-oestrogens on liver might be primarily by activating the antioxidant system. Similar protective mechanisms might be present for enterolactone to protect hepatocytes. However, there is still a lack of experimental evidence. 
Table 3. Multivariate adjusted associations between quartile of enterolactone and serum levels of alanine aminotransferase (ALT), aspartate aminotransferase (AST), alkaline phosphatase (ALP) and $\gamma$-glutamyl transaminase (GGT), National Health and Nutrition Examination Survey (NHANES; $2003-10)^{*}$

(Odds ratios and $95 \%$ confidence intervals)

\begin{tabular}{|c|c|c|c|c|c|c|c|c|c|}
\hline \multirow[b]{3}{*}{ Liver enzyme } & \multirow[b]{3}{*}{ Sex } & \multicolumn{7}{|c|}{ Enterolactone $\dagger$} & \multirow[b]{3}{*}{$P$ for trend } \\
\hline & & \multirow[b]{2}{*}{ Q1 } & \multicolumn{2}{|c|}{ Q2 } & \multicolumn{2}{|c|}{ Q3 } & \multicolumn{2}{|c|}{ Q4 } & \\
\hline & & & OR & $95 \% \mathrm{Cl}$ & OR & $95 \% \mathrm{Cl}$ & OR & $95 \% \mathrm{Cl}$ & \\
\hline \multirow{3}{*}{ ALT } & Total & Ref & 0.93 & $0.73,1.20$ & 0.76 & $0.59,0.99$ & 0.57 & $0.43,0.76$ & 0.57 \\
\hline & Male & Ref & 0.78 & $0.55,1.11$ & 0.74 & $0.50,1.08$ & 0.40 & $0.24,0.66$ & 0.004 \\
\hline & Female & Ref & $1 \cdot 27$ & $0.88,1.84$ & 0.92 & $0.64,1.34$ & 0.73 & $0.50,1.07$ & 0.28 \\
\hline \multirow[t]{3}{*}{ AST } & Total & Ref & 0.83 & $0.65,1.05$ & 0.65 & $0.50,0.84$ & 0.59 & $0.45,0.78$ & 0.06 \\
\hline & Male & Ref & 0.78 & $0.58,1.04$ & 0.59 & $0.42,0.81$ & 0.58 & $0.41,0.81$ & 0.01 \\
\hline & Female & Ref & 1.07 & $0.69,1.68$ & 0.87 & $0.56,1.37$ & 0.66 & $0.42,1.03$ & 0.37 \\
\hline \multirow[t]{3}{*}{ ALP } & Total & Ref & 0.82 & $0.55,1.22$ & 0.75 & $0.50,1.12$ & 0.53 & $0.33,0.83$ & 0.003 \\
\hline & Male & Ref & 0.52 & $0.28,0.99$ & 0.77 & $0.43,1.38$ & 0.44 & $0.21,0.93$ & 0.07 \\
\hline & Female & Ref & $1 \cdot 13$ & $0.66,1.92$ & 0.69 & $0.39,1.23$ & 0.58 & $0.32,1.05$ & 0.01 \\
\hline \multirow[t]{3}{*}{ GGT } & Total & Ref & 0.59 & $0.45,0.76$ & 0.58 & $0.45,0.76$ & 0.37 & $0.27,0.49$ & $<0.001$ \\
\hline & Male & Ref & 0.46 & $0.30,0.69$ & 0.59 & $0.39,0.89$ & 0.37 & $0.22,0.61$ & 0.003 \\
\hline & Female & Ref & 0.72 & $0.51,1.01$ & 0.61 & $0.43,0.87$ & 0.37 & $0.26,0.54$ & 0.009 \\
\hline
\end{tabular}

Ref, reference; GED, General Educational Development; LOD, limit of detection.

${ }^{*}$ Adjusted for age $(20-34,35-49,50-64$ and 65-85 years), sex (male, female) (only in total model), race and ethnicity (Mexican American, other Hispanic, non-Hispanic White, non-Hispanic Black, other), education (less than 9th grade, 9-11th grade, high school/GED), cotinine level (<0.01 (LOD), 0.01-10, and $>10 \mathrm{ng} / \mathrm{ml}$ ), hepatitis $\mathrm{B}$ (positive serum hepatitis B surface antigen and core antibody, negative) and hepatitis $C$ (positive serum hepatitis $C$ antibody, negative), fibre intake (gm). †Quartiles enterolactone (nmol/mg): Q1: $\leq$ 0.032463; Q2:0.032463-0.119347; Q3: 0.119347-0.286198; Q4: >0.286198.

Undoubtedly, oestrogen is crucial to health in females as well as in males. Nevertheless, different concentrations can result in disparate biological effects. Low oestrogen states are associated with certain hepatic diseases, for example, chronic hepatitis B and $\mathrm{C}$ and even cirrhosis. Oestrogen-abundant states are associated with other types of liver abnormalities, such as cholestatic jaundice and benign liver tumours ${ }^{(30)}$. In the past, people commonly used oestrogen replacement therapy in oestrogen deficiency patients ${ }^{(31)}$. Evidence indicates that oestrogen may be a vital pathogenic cofactor in development of alcoholic liver injury ${ }^{(32-35)}$. Oestrogens are also involved in other types of liver disease. Oestrogen leads to damaged mitochondria in acute fatty liver in pregnant women ${ }^{(36)}$ by reducing $\beta$-oxidation of fatty acids and altering the activity of proteins and enzymes in mitochondria.

Enterolactone is a phyto-oestrogen formed in biologically active enterolignan. Seeds, cereals and grains are found to be rich in enterolactone. The mechanism of function for enterolactone is still not quite clear. Enterolactone can decrease oestrogen levels by increasing sex hormone-binding globulin

Table 4. Multivariate adjusted associations between quartile of enterolactone and serum levels of alanine aminotransferase (ALT), aspartate aminotransferase (AST), alkaline phosphatase (ALP) and $\gamma$-glutamyl transaminase (GGT) excluded by hepatitis, National Health and Nutrition Examination Survey (NHANES; 2003-10)*

(Odds ratios and $95 \%$ confidence intervals)

\begin{tabular}{|c|c|c|c|c|c|c|c|c|c|}
\hline \multirow[b]{3}{*}{ Liver enzyme } & \multirow[b]{3}{*}{ Sex } & \multicolumn{7}{|c|}{ Enterolactone† } & \multirow[b]{3}{*}{$P$ for trend } \\
\hline & & \multirow[b]{2}{*}{ Q1 } & \multicolumn{2}{|c|}{ Q2 } & \multicolumn{2}{|c|}{ Q3 } & \multicolumn{2}{|c|}{ Q4 } & \\
\hline & & & OR & $95 \% \mathrm{Cl}$ & OR & $95 \% \mathrm{Cl}$ & OR & $95 \% \mathrm{Cl}$ & \\
\hline \multirow[t]{3}{*}{ ALT } & Total & Ref & 0.89 & $0.68,1.16$ & 0.70 & $0.53,0.93$ & 0.54 & $0.40,0.73$ & 0.39 \\
\hline & Male & Ref & 0.73 & $0.50,1.07$ & 0.64 & $0.42,0.97$ & 0.41 & $0.24,0.69$ & 0.009 \\
\hline & Female & Ref & $1 \cdot 21$ & $0.83,1.78$ & 0.87 & $0.59,1.29$ & 0.66 & $0.44,0.99$ & 0.20 \\
\hline \multirow[t]{3}{*}{ AST } & Total & Ref & 0.81 & $0.62,1.05$ & 0.62 & $0.47,0.81$ & 0.56 & $0.42,0.75$ & 0.10 \\
\hline & Male & Ref & 0.78 & $0.57,1.07$ & 0.55 & $0.39,0.78$ & 0.56 & $0.39,0.81$ & 0.02 \\
\hline & Female & Ref & 0.97 & $0.60,1.57$ & 0.83 & $0.52,1.32$ & 0.58 & $0.36,0.94$ & 0.56 \\
\hline \multirow[t]{3}{*}{ ALP } & Total & Ref & 0.80 & $0.52,1.21$ & 0.73 & $0.48,1.12$ & 0.48 & $0.29,0.78$ & 0.002 \\
\hline & Male & Ref & 0.48 & $0.24,0.97$ & 0.77 & $0.42,1.44$ & 0.49 & $0.23,1.04$ & $0 \cdot 10$ \\
\hline & Female & Ref & 1.09 & $0.63,1.89$ & 0.66 & $0.37,1 \cdot 20$ & 0.46 & $0.24,0.88$ & 0.007 \\
\hline \multirow[t]{3}{*}{ GGT } & Total & Ref & 0.56 & $0.42,0.74$ & 0.56 & $0.42,0.74$ & 0.33 & $0.24,0.46$ & 0.001 \\
\hline & Male & Ref & 0.45 & $0.29,0.71$ & 0.51 & $0.33,0.81$ & 0.32 & $0.18,0.56$ & 0.003 \\
\hline & Female & Ref & 0.67 & $0.46,0.96$ & 0.62 & $0.43,0.88$ & 0.35 & $0.23,0.52$ & 0.02 \\
\hline
\end{tabular}

Ref, reference; GED, General Educational Development; LOD, limit of detection.

${ }^{*}$ Adjusted for age (20-34, 35-49, 50-64 and 65-85 years), sex (male, female) (only in total model), race and ethnicity (Mexican American, other Hispanic, non-Hispanic

White, non-Hispanic Black, other), education (less than 9th grade, 9-11th grade, high school/GED), cotinine level (<0.01 (LOD), 0.01-10 and $>10 \mathrm{ng} / \mathrm{ml}$ ), fibre intake (gm). †Quartiles enterolactone (nmol/mg): Q1: $\leq$ 0.032463; Q2:0.032463-0.119347; Q3: 0.119347-0.286198; Q4: >0.286198. 
concentration $^{(37)}$ and reducing aromatase activity ${ }^{(38)}$, leading to low concentrations of free oestrogen. Although previous research has suggested that enterolactone possesses low binding affinities to $\mathrm{ER} \alpha$ and $\mathrm{ER} \beta^{(39)}$, Penttinen et al. ${ }^{(40)}$ found activation by ER $\beta$ required a higher enterolactone concentration than $\mathrm{ER} \alpha$. These data suggest the existence of a cell type-specific and tissue-specific activity of enterolactone. Moreover, non-hormonal effects of enterolactone for inhibition of the development of breast cancer, including antioxidative effects ${ }^{(41)}$ and an inhibitory effect on angiogenesis, were demonstrated ${ }^{(42)}$. Enterolactone is produced by the gut microbiota and reabsorbed in the intestine, undergoing enterohepatic circulation. The metabolism of lignans to enterolignans (enterolactone and enterodiol) is mainly through gut micro-organisms. Different gut microbial environments have various enterolignan concentrations in the host. Thus, the gut microbiota may be a major determinant of enterolactone absorption ${ }^{(43)}$. However, urinary enterolactone levels may reflect the metabolism of enterolignans by gut microbiota, which has proved important in liver disease ${ }^{(44)}$.

There are several limitations to the present study. First, although we adjusted for potential confounders, some confounders such as physical activity and genetic susceptibility were not recorded and adjusted for in the analysis. In addition to the common covariants, we analysed other covariants that may influence abnormal liver enzyme levels, such as diabetes, which ensured that the present study results reflected reality. Because the study was cross sectional, it is not possible to know whether phyto-oestrogens affected liver enzymes or vice versa.

In summary, the present study results revealed that enterolactone exposure may be associated with favourable liver health in male and female adults. Future studies are needed to confirm this and explore potential mechanisms.

\section{Supplementary material}

To view supplementary material for this article, please visit http://dx.doi.org/10.1017/S000711451500149X

\section{Acknowledgements}

The present study was supported by the National Natural Science Foundation of China (to A. G., grant no. 81172694; to Z.-Y. J., grant no. 81270537); the Outstanding Youth Fund of Jiangsu Province (to A. G., grant no. SBK2014010296), the Research Project of the Chinese Ministry of Education (to A. G., grant no. 213015A); the Jiangsu Province's Qinglan project (to A. G., grant no. JX2161015124); and the Project Funded by the Priority Academic Program Development of Jiangsu Higher Education Institutions. The sponsors had no role in study design; data abstraction, analysis, and interpretation; or writing of the manuscript.

We thank the many people who have contributed to the NHANES data, including all of the anonymous participants in the study.

The authors' contributions are as follows: Q. L. and C. X. conducted the data analyses; Z.-Y. J. and A. G. were involved in the design of the study and interpretation of the results, and critically reviewed the manuscript. All authors approved the final manuscript.

The authors declare that they have no conflicts of interests to declare.

\section{References}

1. Humfrey CD (1998) Phytoestrogens and human health effects: weighing up the current evidence. Nat Toxins 6, 51-59.

2. Younes M \& Honma N (2011) Estrogen receptor beta. Arch Pathol Lab Med 135, 63-66.

3. Paterni I, Granchi C, Katzenellenbogen JA, et al. (2014) Estrogen receptors alpha (ERalpha) and beta (ERbeta): subtype-selective ligands and clinical potential. Steroids $\mathbf{9 0}$, $13-29$.

4. Bar-El DS \& Reifen R (2010) Soy as an endocrine disruptor: cause for caution? J Pediatr Endocrinol Metab 23, 855-861.

5. Bilal I, Chowdhury A, Davidson J, et al. (2014) Phytoestrogens and prevention of breast cancer: the contentious debate. World J Clin Oncol 5, 705-712.

6. Hwang YW, Kim SY, Jee SH, et al. (2009) Soy food consumption and risk of prostate cancer: a meta-analysis of observational studies. Nutr Cancer 61, 598-606.

7. Frankenfeld CL (2014) Cardiometabolic risk factors are associated with high urinary enterolactone concentration, independent of urinary enterodiol concentration and dietary fiber intake in adults. J Nutr 144, 1445-1453.

8. Struja T, Richard A, Linseisen J, et al. (2014) The association between urinary phytoestrogen excretion and components of the metabolic syndrome in NHANES. Eur J Nutr 53, 1371-1381.

9. Choi EJ \& Kim GH (2009) Hepatoprotective effects of daidzein against 7,12-dimetylbenz[a]anthracene-induced oxidative stress in mice. Int J Mol Med 23, 659-664.

10. Mohamed Salih S, Nallasamy P, Muniyandi P, et al. (2009) Genistein improves liver function and attenuates nonalcoholic fatty liver disease in a rat model of insulin resistance. J Diabetes 1, 278-287.

11. Fan YJ, Rong Y, Li PF, et al. (2013) Genistein protection against acetaminophen-induced liver injury via its potential impact on the activation of UDP-glucuronosyltransferase and antioxidant enzymes. Food Chem Toxicol 55, 172-181.

12. National Health and Nutrition Examination Survey (2012) Questionnaires, datasets and related documentation: NHANES 1999-2010. http://www.cdc.gov/nchs/nhanes.htm (accessed 23 December 2014).

13. National Center for Health Statistics (2010) Hyattsville MCfDCaP. National Health and Nutrition Examination Survey 2001-2002 Lab Methods. http://www.cdc.gov/nchs/ nhanes/nhanes2001-2002/lab_methods_01_02.htm

14. Engelhardt PF \& Riedl CR (2008) Effects of one-year treatment with isoflavone extract from red clover on prostate, liver function, sexual function, and quality of life in men with elevated PSA levels and negative prostate biopsy findings. Urology 71, 185-190.

15. Barsalani R, Riesco E, Lavoie JM, et al. (2013) Effect of exercise training and isoflavones on hepatic steatosis in overweight postmenopausal women. Climacteric 16, 88-95.

16. Manonai J, Chittacharoen A, Udomsubpayakul U, et al. (2008) Effects and safety of Pueraria mirifica on lipid profiles and biochemical markers of bone turnover rates in healthy postmenopausal women. Menopause 15, 530-535.

17. Rietjens IM, Sotoca AM, Vervoort J, et al. (2013) Mechanisms underlying the dualistic mode of action of major soy 
isoflavones in relation to cell proliferation and cancer risks. Mol Nutr Food Res 57, 100-113.

18. Wang LQ (2002) Mammalian phytoestrogens: enterodiol and enterolactone. J Chromatogr B Analyt Technol Biomed Life Sci 777, 289-309.

19. Cassidy A (2003) Potential risks and benefits of phytoestrogen-rich diets. Int J Vitam Nutr Res 73, 120-126.

20. Bottner M, Thelen P \& Jarry H (2014) Estrogen receptor beta: tissue distribution and the still largely enigmatic physiological function. J Steroid Biochem Mol Biol 139, 245-251.

21. Vina J, Gambini J, Lopez-Grueso R, et al. (2011) Females live longer than males: role of oxidative stress. Curr Pharm Des 17, 3959-3965.

22. Bourque M, Dluzen DE \& Di Paolo T (2012) Signaling pathways mediating the neuroprotective effects of sex steroids and SERMs in Parkinson's disease. Front Neuroendocrinol 33, 169-178

23. Ming LG, Chen KM \& Xian CJ (2013) Functions and action mechanisms of flavonoids genistein and icariin in regulating bone remodeling. J Cell Physiol 228, 513-521.

24. Yanagihara N, Zhang H, Toyohira Y, et al. (2014) New insights into the pharmacological potential of plant flavonoids in the catecholamine system. J Pharmacol Sci 124, 123-128.

25. Kurzer MS \& Xu X (1997) Dietary phytoestrogens. Annu Rev Nutr 17, 353-381

26. Fu Z, Zhang W, Zhen W, et al. (2010) Genistein induces pancreatic beta-cell proliferation through activation of multiple signaling pathways and prevents insulin-deficient diabetes in mice. Endocrinology 151, 3026-3037.

27. Lim U \& Song MA (2012) Dietary and lifestyle factors of DNA methylation. Methods Mol Biol 863, 359-376.

28. Hajirahimkhan A, Dietz BM \& Bolton JL (2013) Botanical modulation of menopausal symptoms: mechanisms of action? Planta Med 79, 538-553.

29. Wong MC, Portmann B, Sherwood R, et al. (2007) The cytoprotective effect of alpha-tocopherol and daidzein against d-galactosamine-induced oxidative damage in the rat liver. Metabolism 56, 865-875.

30. Lockhat D, Katz SS, Lisbona R, et al. (1981) Oral contraceptives and liver disease. Can Med Assoc J 124, 993-999.

31. Belchetz PE (1994) Hormonal treatment of postmenopausal women. N Engl J Med 330, 1062-1071.

32. Pares A, Caballeria J, Bruguera M, et al. (1986) Histological course of alcoholic hepatitis. Influence of abstinence, sex and extent of hepatic damage. J Hepatol 2, 33-42.
33. Loft S, Olesen KL \& Dossing M (1987) Increased susceptibility to liver disease in relation to alcohol consumption in women. Scand J Gastroenterol 22, 1251-1256.

34. Norton R, Batey R, Dwyer T, et al. (1987) Alcohol consumption and the risk of alcohol related cirrhosis in women. Br Med J (Clin Res Ed) 295, 80-82.

35. Iimuro Y, Frankenberg MV, Arteel GE, et al. (1997) Female rats exhibit greater susceptibility to early alcoholinduced liver injury than males. Am $J$ Physiol 272, G1186-G1194.

36. Grimbert S, Fisch C, Deschamps D, et al. (1995) Effects of female sex hormones on mitochondria: possible role in acute fatty liver of pregnancy. Am J Physiol 268, G107-G115.

37. Low YL, Dunning AM, Dowsett M, et al. (2007) Phytoestrogen exposure is associated with circulating sex hormone levels in postmenopausal women and interact with ESR1 and NR1I2 gene variants. Cancer Epidemiol Biomarkers Prev 16, 1009-1016.

38. Brooks JD \& Thompson LU (2005) Mammalian lignans and genistein decrease the activities of aromatase and 17beta-hydroxysteroid dehydrogenase in MCF-7 cells J Steroid Biochem Mol Biol 94, 461-467.

39. Mueller SO, Simon S, Chae K, et al. (2004) Phytoestrogens and their human metabolites show distinct agonistic and antagonistic properties on estrogen receptor alpha (ERalpha) and ERbeta in human cells. Toxicol Sci 80, 14-25.

40. Penttinen P, Jaehrling J, Damdimopoulos AE, et al. (2007) Diet-derived polyphenol metabolite enterolactone is a tissue-specific estrogen receptor activator. Endocrinology 148, 4875-4886.

41. Prasad K (2000) Antioxidant activity of secoisolariciresinol diglucoside-derived metabolites, secoisolariciresinol, enterodiol, and enterolactone. Int J Angiol 9, 220-225.

42. Bergman Jungestrom M, Thompson LU \& Dabrosin C (2007) Flaxseed and its lignans inhibit estradiol-induced growth, angiogenesis, and secretion of vascular endothelial growth factor in human breast cancer xenografts in vivo. Clin Cancer Res 13, 1061-1067.

43. Sonestedt E \& Wirfalt E (2010) Enterolactone and breast cancer: methodological issues may contribute to conflicting results in observational studies. Nutr Res 30, 667-677.

44. Qin N, Yang F, Li A, et al. (2014) Alterations of the human gut microbiome in liver cirrhosis. Nature 513, 59-64. 